\title{
Use of image transformation to track the natural history of diseases
}

\author{
This article was published in the following Dove Press journal: \\ Pragmatic and Observational Research \\ 29 September 2010 \\ Number of times this article has been viewed
}

\begin{abstract}
Albert Shar
Information Technology, Robert Wood Johnson Foundation, Princeton, New Jersey, USA
\end{abstract}

Abstract: The inability to precisely measure the area of a lesion can impair the study of its natural history and response to therapy. This is especially true in case of gastrointestinal lesions, where a standard imaging technique is endoscopy and an unaided visual interpretation of the size of the lesion is difficult. This study presents a novel technique that provides precise measurement of 2-dimensional lesions in cylinder-like organs.

Keywords: quantitative endoscopy, Barrett's esophagus, lesion measurement, disease tracking

The inability to precisely measure the area of a lesion can impair the study of its natural history and response to therapy. This is especially true in case of gastrointestinal lesions, where a standard imaging technique is endoscopy. In endoscopy, the perceived size of a structure is mostly a function of the distance to the lens. The purpose of this study is to discuss a novel technique (US patent number 7,011,625) that translates and stacks sequential endoscopic images into 2-dimensional maps, where areas can be precisely measured and compared over time. Although the process has been used in 3 clinical trials ( 2 in the United States and 1 in China), it is not yet commercially available.

The technique is best described graphically. If one thinks of the structure as essentially tubular, then conceptually, the process is to slice and then "flatten" a section of the tube. A series of photographs is taken as the scope moves up or down, and the resulting rectangular regions are then tied together as is depicted in Figure 1.

The mathematics necessary to convert the images is essentially a transformation ${ }^{1}$ (adjusted both for lens characteristics and for mapping of angle measurements to distances) from polar to rectangular coordinates:

$$
(x, y) \rightarrow\left(\arctan \frac{x}{r}, r\right) \text {-where } r=\sqrt{x^{2}+y^{2}}
$$

It has been shown that the technique provides accurate area measurements and is replicable. ${ }^{2,3}$

In the Chemoprevention for Barrett's Esophagus Trial ${ }^{4}$ (a multisite clinical trial to test whether a COX-2 inhibitor would prevent esophageal cancers in patients with Barrett's esophagus), the technique was used to analyze changes in lesion size over time. ${ }^{4,5}$ Figure 2 shows the images of the transformations. Two series of 3 images are shown. The first row was taken at baseline and the second row was taken at 48-week follow-up. The baseline and 48-week follow-up images were of the same region in the
Correspondence: Albert Shar

Robert Wood Johnson Foundation,

Rte I and College Rd E, PO Box 2316,

Princeton, New Jersey 08543-2316, USA

Tel + I 609-627-5873

$\mathrm{Fax}+\mathrm{I} 609-419-8333$

Email ashar@rwjf.org
Pragmatic and Observational Research 2010:1 II-13

(C) 2010 Shar, publisher and licensee Dove Medical Press Ltd. This is an Open Access article

Dovepress

which permits unrestricted noncommercial use, provided the original work is properly cited. 

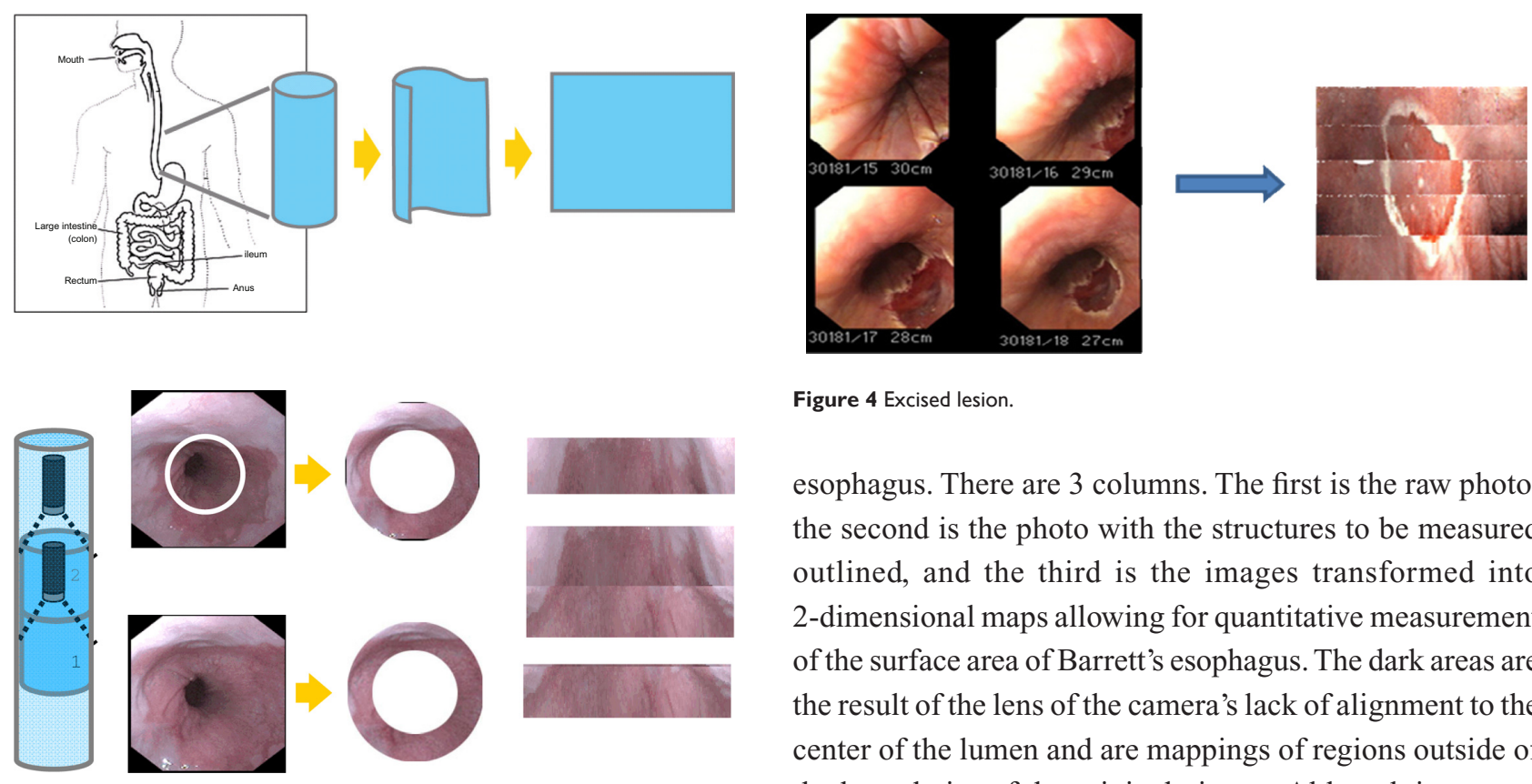

Figure I Image transformation and stacking.

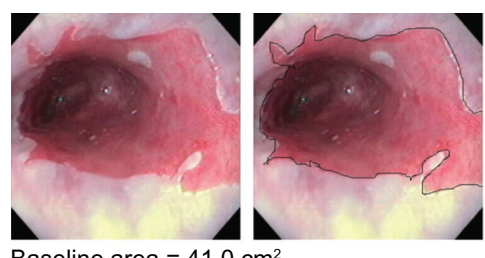

Baseline area $=41.0 \mathrm{~cm}^{2}$

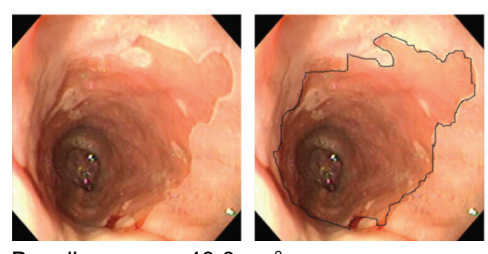

Baseline area $=40.0 \mathrm{~cm}^{2}$

Figure 2 Barrett's esophagus transformations.

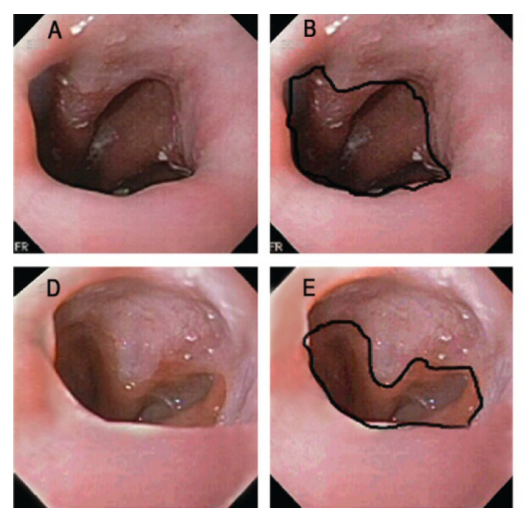

Figure 3 Ablative treatment.
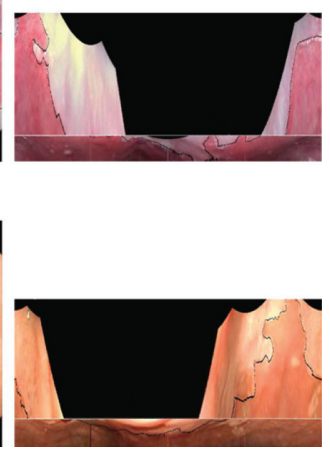

Figure 4 Excised lesion.

esophagus. There are 3 columns. The first is the raw photo, the second is the photo with the structures to be measured outlined, and the third is the images transformed into 2-dimensional maps allowing for quantitative measurement of the surface area of Barrett's esophagus. The dark areas are the result of the lens of the camera's lack of alignment to the center of the lumen and are mappings of regions outside of the boundaries of the original picture. Although it was not possible to demonstrate a chemopreventive drug effect using the standard techniques, an alternative and novel analysis ${ }^{6}$ did show significance.

In an unpublished randomized control ablative therapy trial in patients with Barrett's esophagus, the techniques were again used (Figure 3). In this case, although ablation significantly reduced the lesion, there was no effect using a chemopreventive agent.

The previous 2 examples are ones where the goal was to accurately measure the change in the size of a precancerous lesion over time. The same process can be used to measure
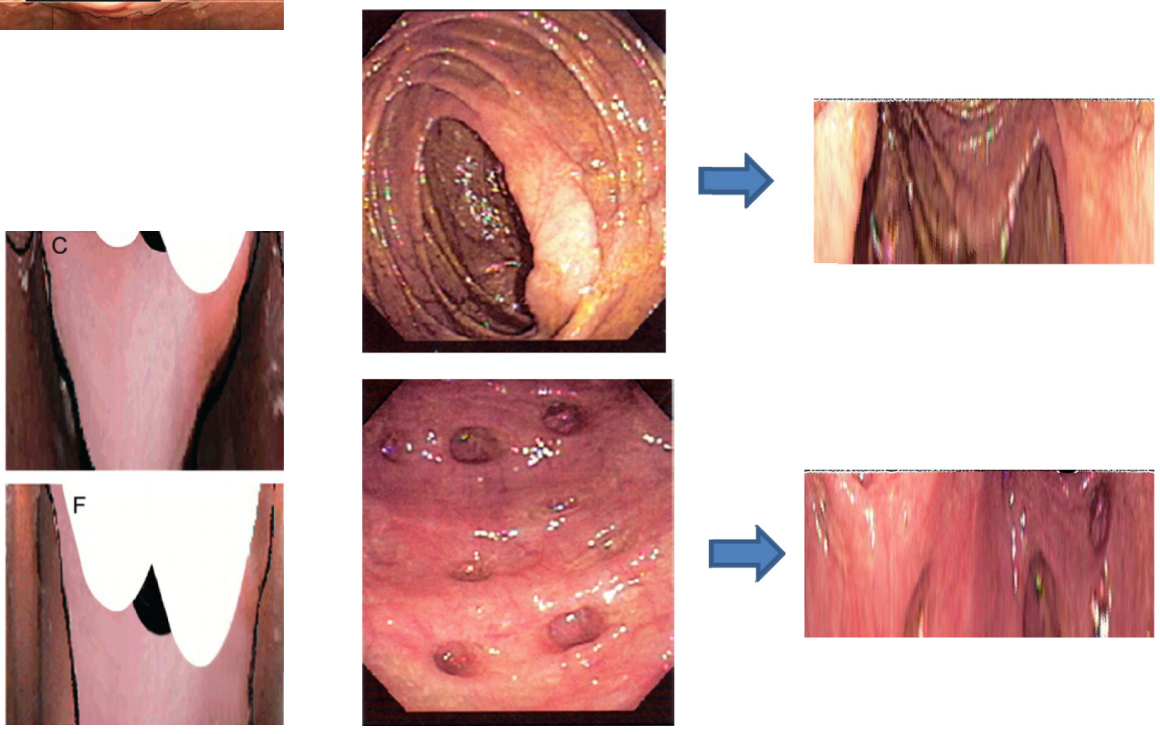

Figure $\mathbf{5}$ Image transformation in the colon. 
the shape and size of a tissue that has been excised. Figure 4 shows the reconstruction of an excised squamous cell esophageal carcinoma. This analysis is from an unpublished study conducted in China.

Although the above examples are all involved with the esophagus, the technique applies to any hollow cylindrical structure into which one can place and align a camera. Figure 5 shows the images of the colon from a routine colonoscopy that have been transformed.

\section{Acknowledgment}

The author is the holder of the patented technology used.

\section{Disclosure}

This work is that of the author and does not imply any endorsement by or position of the Robert Wood Johnson Foundation.

\section{References}

1. Shar AO, Baggott BB, Reynolds JC. Computer enhanced endoscopic visualization. Proc Annu Symp Comput Appl Med Care. 1990; 544-546.

2. Kim R, Baggott BB, Rose S, et al. Quantitative endoscopy: precise computerized measurement of metaplastic epithelial surface area in Barrett's esophagus. Gastroenterology. 1995;108(2):360-366.

3. Kim R, Rose S, Shar AO, Weiner M, Reynolds JC. Extent of Barrett's metaplasia: a prospective study of the serial change in area of Barrett's measured by quantitative endoscopic imaging. Gastrointest Endosc. 1997;45(6):456-462.

4. Heath EI, Canto MI, Wu TT, et al. Chemoprevention for Barrett's esophagus trial. Design and outcome measures. Dis Esophagus. 2003; 16(3):177-186.

5. Heath EI, Canto MI, Piantadosi S, et al. Secondary chemoprevention of Barrett's esophagus with Celecoxib. J Natl Cancer Inst. 2007;99(7): $545-557$.

6. Shar AO, Gaudard MA, Heath EI, Forastiere AA, Yang VW, Sontag SJ. Modeling using baseline characteristics in a small multicenter clinical trial for Barrett's esophagus. Contemp Clin Trials. 2009;30(1):2-7.
Pragmatic and Observational Research

\section{Publish your work in this journal}

Pragmatic and Observational Research is an international, peer-reviewed, open access journal that publishes data from studies designed to reflect more closely medical interventions in real-world clinical practice compared with classical randomized controlled trials (RCTs). The manuscript

\section{Dovepress}

management system is completely online and includes a very quick and fair peer-review system. 